Such insight could help to design receptor-specific therapeutics and limit side effects, the authors say. Science http://dx.doi.org/ 10.1126/science.1232807 (2013); Science http://dx.doi. org/10.1126/science.1232808 (2013)

For a longer story on this research, see go.nature.com/yw8pdm

\section{NEUROIMAGING}

\section{Single cells seen in whole brains}

A fast imaging technique can monitor the activity of individual neurons across the brain of fish larvae, providing both a detailed and comprehensive view of a vertebrate brain.

Misha Ahrens and Philipp Keller at Janelia Farm Research Campus in Ashburn, Virginia, imaged the brains of transparent larval zebrafish (Danio rerio), which had been engineered to have neurons that fluoresce when active. The authors improved on a technique that uses planes of laser light to capture images layer by layer, called light-sheet microscopy, by increasing the imaging speed. The method could cover the full brain of a 5-day-old zebrafish larva every 1.3 seconds, detecting more than $80 \%$ of its 100,000-odd neurons at the single-cell level (pictured).

Such images can help researchers to map activity

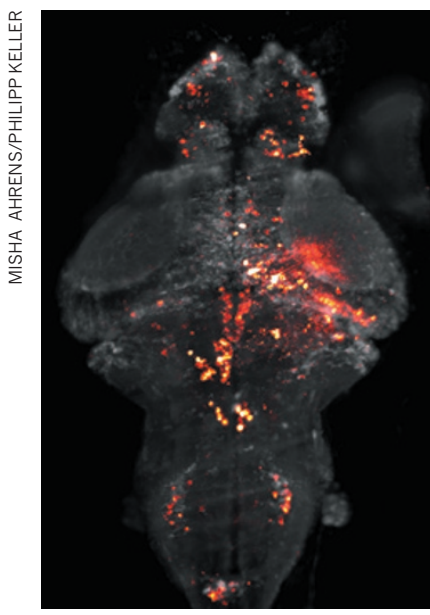

across the brain and show which parts of the brain function together, the researchers say.

Nature Meth. http://dx.doi. org/10.1038/nmeth.2434 (2013) For a longer story on this research, see go.nature.com/f8dtkd

\section{OBESITY \\ Fat cells use immune signal}

In obese individuals, fat cells may act like inflammatory white blood cells by using communication machinery once considered to be exclusive to immune cells.

High numbers of several types of immune cell patrol the fat tissues of people who are obese. This inflammation is highly correlated with health risks such as insulin resistance and metabolic syndrome, although how it gets started is unclear. Willa Hsueh and her colleagues at the Methodist Hospital in Houston, Texas, show that it may begin with adipocytes, or fat cells. The authors compared gene expression in lean and obese women and noticed that adipocytes expressed many genes connected to the major histocompatibility complex II, which certain white blood cells use to activate other white blood cells. An array of follow-up studies in mice fed high-fat diets indicate that it is the fat cells themselves that prompt inflammation.

The researchers suggest that obesity triggers alterations in fat cells that are then escalated by white blood cells.

Cell Metab. 17, 411-422 (2013)

Origins of the
ear lining

In mammalian embryos, the middle-ear chamber starts as a pouch that pokes out from the oral cavity. The roof of this cavity ruptures and fills with cells that then retract up over the bones of the middle ear, leaving an air-filled space.

Hannah Thompson and

COMMUNITY CHOICE

The most viewed papers in science

CHEMISTRY

\title{
Long DNA-like chains assemble
}

HIGHLY READ
on www.acs.org
in February

Extremely long molecular chains can self-assemble from two nucleobaselike chemicals, report Nicholas Hud at the Georgia Institute of Technology in Atlanta, and his co-workers.

The team showed that three of each of the monomers cyanuric acid and a pyrimidine derivative can form a rosette structure. When combined in water, the rosettes stacked themselves into long chains that were more than 1 micrometre in length, the longest self-assembling watersoluble structures ever made from such small molecules. Hydrogen bonding and stacking between the monomers was similar to that seen between individual nucleobases in DNA and RNA. The work provides insight into how a self-assembling system might have existed in a prebiotic world.

J. Am. Chem. Soc. 135, 2447-2450 (2013)

Abigail Tucker at King's College London looked at mice genetically engineered such that the descendants of cells in the developing ear could be tracked. This revealed a double origin for the epithelial cells within the cavity, and thus in two cell types. Cells lining the bottom of the cavity are thick and have cilia that robustly sweep away debris. Cells lining the roof are flat and offer little protection from debris or inflammation. The way in which the mammalian ear develops and our susceptibility to middleear infections may be related, the authors suggest.

Science 339, 1453-1456 (2013)

\section{PLANETARY SCIENCE}

\section{Migrating planets sped up collisions}

The pockmarked asteroid Vesta (pictured) has provided more hints about the history of the early Solar System.

As giant planets such as Jupiter and Saturn shifted into place about 4.1 billion years ago, their changing gravitational pull flung asteroid fragments into highly eccentric orbits. Those space

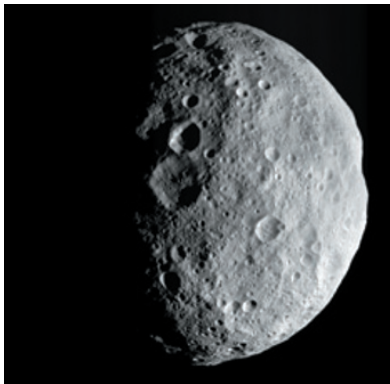

rocks, in turn, slammed into other asteroids at high speed, heating them and altering their chemistry.

This scenario, proposed by Simone Marchi at the Southwest Research Institute in Boulder, Colorado, and his colleagues, could explain why the asteroid Vesta was pummelled so frequently between 4.1 billion and 3.4 billion years ago. The team's simulations suggest that meteors were slung at much higher velocities than once thought, for a period that lasted hundreds of millions of years.

Nature Geosci. http://dx.doi. org/10.1038/ngeo1769 (2013)

\section{$\rightarrow$ NATURE.COM}

For the latest research published by Naturevisit:

www.nature.com/latestresearch 